\title{
Physical and Mechanical Properties of Engineered Coconut Trunk Veneer (ECTV) for Interior Products
}

\author{
Yanti A.K ${ }^{1}$., Said A. ${ }^{1}$, A. Hamid S. ${ }^{2}$, Hamdan H. ${ }^{2}$, Izran K. ${ }^{2}$, \\ Khairul M. ${ }^{2}$, Razali A.K. ${ }^{1}$ and Azrena A.K. ${ }^{2}$
}

\begin{abstract}
A study was undertaken to investigate the physical and mechanical properties of engineered coconut (Cocos nucifera) veneer (ECTV). The coconut trunks (40 - 50 years old) were obtained from Hutan Melintang, Perak and were peeled into veneers at Bestgrade Sdn. Bhd. The veneers were obtained from two different parts of coconut trunks viz inner and outer which were used to fabricate 5ply engineered coconut veneers. The ECTVs were fabricated at FRIM's Bio-Composite Laboratory. They were manufactured with urea formaldehyde (UF) resin and with three combinations namely $100 \%$ inner, $100 \%$ outer and alternate outer \& inner veneers (mix). The densities for the engineered veneers made of $100 \%$ outer, $100 \%$ inner, and mixed layers were $944.1 \mathrm{~kg} / \mathrm{m}^{3}, 858.15 \mathrm{~kg} / \mathrm{m}^{3}$ and $891.11 \mathrm{~kg} / \mathrm{m}^{3}$, respectively. Results showed that the Modulus of Rupture (MOR) of the ECTV made from $100 \%$ outer veneers had the highest mean MOR value (88.69 MPa), followed by those made from the mixed veneers $(74.35 \mathrm{MPa})$ and $100 \%$ inner $(58.44 \mathrm{MPa})$, respectively. On the other hand, the Modulus Of Elasticity (MOE) values were 10.12 Mpa for outer, 8,210 Mpa for inner and 10,075 Mpa for mixed. Overall, the testing results showed that the ECTV met the standard requirements.
\end{abstract}

Keywords: coconut trunk veneers, urea formaldehyde, physical and mechanical properties.

${ }^{1}$ Faculty of Applied Science, University Technology MARA, Shah Alam, Malaysia.

${ }^{2}$ Forest Research Institute Malaysia (FRIM), 52109 Kepong, Selangor, Malaysia.

Email: izrankamal@frim.gov.my 


\section{Introduction}

Furniture industry is one of the most important sectors to help in increasing Malaysia's economic growth. Unsustainable supply of timber for wood-based industry is one of the issues raised by the industry. Manufacturers that are producing wood-based products feel the burden caused by the unsustainable supply of wood; hence they are searching for a cheaper material but have almost similar properties to wood to ensure continuous supply of material for their productions.

Besides oil palm trunk, coconut trunk is another alternative raw material in wood-based, plywood and furniture manufacturing.

The supply of the material is expected to increase due to the continuous demand for coconut fruits, medicine and food industry (Siva, 2009). In Malaysia currently coconut trunk is less utilized material and sold at very low price. Abundance of coconut trunk supply is available in Malaysia, as shown in table 1 about 114,730 ha were planted with coconut in 2008 and coconut is the fourth most important crop after oil palm, rubber and paddy. If the coconut trunks can be transformed to value added products as alternative raw material will nevertheless reduce the problem of unstable supply of wood based material.

Therefore this research was conducted with the basic objective of evaluating the physical and mechanical properties of the engineered coconut trunk veneer bonded with urea formaldehyde resin and diversifying the use of the trunks to highlight its potential as a material for engineered wood veneer.

Table 1. Total area planted with coconut trees in Malaysia (hectare)

\begin{tabular}{lrrr}
\hline \multirow{2}{*}{ State } & \multicolumn{3}{c}{ Year } \\
\cline { 2 - 4 } & $\mathbf{2 0 0 6}$ & $\mathbf{2 0 0 7}$ & $\mathbf{2 0 0 8}$ \\
\hline Peninsular & 76,953 & 75,035 & 73,355 \\
Sabah & 18,245 & 18,060 & 17,760 \\
Sarawak & 23,681 & 23,440 & 23,120 \\
WP Labuan & 585 & 565 & 495 \\
\hline Total & $\mathbf{1 1 9 , 4 6 4}$ & $\mathbf{1 1 7 , 1 0 0}$ & $\mathbf{1 1 4 , 7 3 0}$ \\
\hline
\end{tabular}

Sources: MOA 2009

\section{Materials and Methods}

\section{Materials}

The coconut trunks in this investigation were harvested from a plantation area in Hutan Melintang, Kuala Selangor. A total of five trees with age ranges between $40-50$ years-old were harvested randomly. After felling, the trunks were transported to Besgrade Sdn. Bhd. The coconut trunk was cut and peeled using a spindles lathe rotary veneer machine. The targeted veneer size was $1200 \mathrm{~mm}$ (length) $\mathrm{x}$ $600 \mathrm{~mm}$ (width) x $4 \mathrm{~mm}$ (thickness) and the final products were segregated into outer and inner veneer. The segregation were done visually by looking at their colour variation. The outer veneer has darker colour than inner. The veneers were dried in the roller conveyer dryer, at a temperature of about $100 \pm 2^{\circ} \mathrm{C}$, for 30 minutes to achieve the final moisture content (MC) below $10 \%$. After the drying process, the veneers were wrapped separately according to inner and outer and taken to FRIM for further processing.

The binder used in this study was Urea Formaldehyde (UF) supplied by Malayan Adhesives \& Chemicals Sdn. Bhd. This is because the target final use is for interior products such as wall paneling, top and furniture component.

\section{Preparation of ECTV}

In FRIM, the coconut trunk veneers (CTV) were cut to a dimension of $400 \mathrm{~mm}$ (length) $\mathrm{x}$ $400 \mathrm{~mm}$ (width) x $4 \mathrm{~mm}$ (thickness). The MC was re-checked using moisture meter and should read below $10 \%$ MC. If the MC of the veneer is higher it may cause blistering onto the final product surface. The 5 layer veneers were arranged perpendicular to grain similar to plywood, as shown in Figure 1. Three different configurations of panel product were produced for this test, namely panel made of inner veneer $100 \%$ (IV), outer veneer $100 \%$ (OV), mixture of outer and inner veneer (MV).

After gluing with UF (the glue spread was, the CTEV panels were pre-pressed (cold press) for about 20 minutes. It is subsequently hotpressed machine for 10 minutes, with a pressure 
Figure 1. Arrangement of veneers

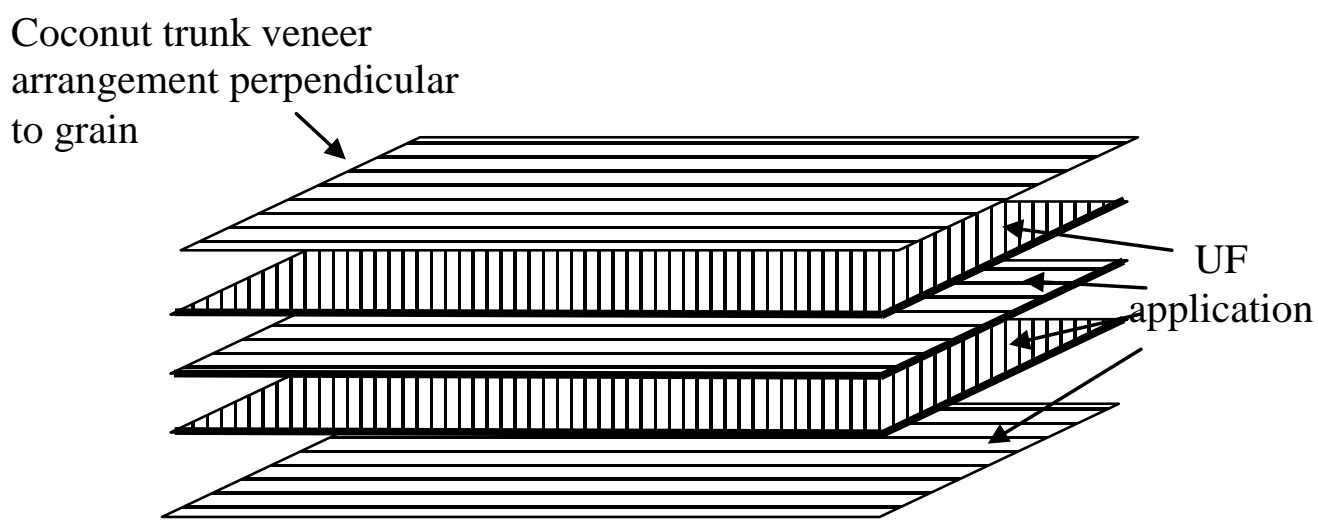

at $500 \mathrm{psi}\left(35.15 \mathrm{~kg} / \mathrm{cm}^{2}\right)$ and a temperature of $100^{\circ} \mathrm{C}$. After hot pressing, the CTEV panels were stored in a conditioning room at a temperature of $25^{\circ} \mathrm{C}$ and $65 \%$ relative humidity for one week before the cutting process.

The conditioned ECTV panels then were cut into specific sizes for testing in accordance to British-European Standard. The mechanical properties test conducted were static bending Modulus Of Elasticity (MOE) and Modulus Of Rupture (MOR) according to BS EN 310:1993, and screw withdrawal test (BS EN 5669:1989). For the determination of physical properties, the tests include moisture content and density determination (BS EN 323:1993), thickness swelling and water absorption (BS EN 317:1993).

\section{Results and Discussion}

Engineered coconut trunk veneers (ECTV) panels were successfully produced from coconut trunks at 3 different veneer configurations. The objectives of the study were to determine the physical and mechanical properties of the panel at different configuration between inner zone, outer zone and combination of both inner and outer veneer for ECTV.

\section{Mechanical Properties}

Table 2 shows the result of the physical and mechanical tests conducted on coconut veneer panels. The range of MOE for the three ECTVs is from 8,210.13Mpa to 10,076.28 Mpa, with the outer ECTV getting the highest value at 10,124.07 Mpa. These values have surpassed the BS EN 314:1996 minimal value for indoor panel, which is $3,000 \mathrm{Mpa}$. The values of MOR for all the ECTVs tested as shown in Table 2 are 58.44Mpa, 74.35Mpa and 86.66Mpa. All three also surpassed the minimum standard requirement which is $18 \mathrm{Mpa}$ with the ECTV from the outer layer veneers having the highest value. The high value at the outer layer is mainly due to the percentage of vascular bundle and fibre areas present which are significantly higher at the outer part than inner part of the cylinder (Ling et. all, 2004).

\section{Physical Properties}

The result in Table 2 showed that the outer ECTV has the highest density value at 944.14 $\mathrm{kg} / \mathrm{m}^{3}$ while the inner ECTV have the lowest density with value of $858.15 \mathrm{~kg} / \mathrm{m}^{3}$. While the moisture content of the ECTV ranges from $8.77 \%$ to $6.37 \%$ with the inner recoding the highest. Thickness swelling value ranges from 
Table 2. Physical and Mechanical Properties of ECTV

\begin{tabular}{lrrr}
\hline \multicolumn{1}{r}{ Testing } & Inner ECTV & Combination ECTV & Outer ECTV \\
\hline MOR (Mpa) & 58.44 & 74.35 & 86.66 \\
MOE (Mpa) & $8,210.13$ & $10,076.28$ & $10,124.07$ \\
SW (N) & 1099 & 1201 & 1901 \\
MC (\%) & 8.77 & 8.30 & 6.37 \\
Density $\left(\mathrm{kg} / \mathrm{cm}^{3}\right)$ & 858.15 & 891.10 & 944.14 \\
TS $(\%)$ & 9.29 & 7.64 & 6.35 \\
\hline
\end{tabular}

MOR $=$ Modulus Of Rupture, $\mathrm{MOE}=$ Modulus Of Elasticity,

SW $=$ Screw Withdrawal, MC=Moisture Content, TS $=$ Thickness Swelling

$6.35 \%$ to $9.29 \%$ for the ECTV and is acceptable according to BS EN which below 14\%. The results clearly show the strong correlation between the anatomical characteristics and location within the coconut trunk with the physical properties.

\section{Conclusions}

The finding from the study found that all three ECTV either outer, inner and combination of both can be used as panel, wooden components for furniture and interior product. The properties obtained from the series of tests conducted showed that ECTV is comparable to tropical hardwood and all test carried, passed the British European Standard. This shows that veneer from coconut trunk can be use for various types of value added products and should be recommended into the re-plantation program in Malaysia to ensure the sustainability of the raw material supply.

\section{References}

BS EN 323:1993, Wood-based panels. Determination of density.

BS EN 310:1993, Wood-based panels. Determination of modulus of elasticity in bending and bending strength.

BS EN 317:1993, Particleboards and fibre boards. Determination of swelling and thickness after immersion in water.
Ling-Long Kuo Huang, Yang San Huang, ShinShin Chen and Yi Ru Huang. 2004. Growth stress and related Anatomical Characteristics in the coconut palm trees. IAWA Journal 25 (3), 297-310.

Minister of Agriculture. January 2009, Laporan Profil Kelapa, Kementerian Pertanian dan Asas Tani. (Online: www.moa.gov.my; accessed 15 March 2010).

Sivapragasam, A. 2008. Coconut in Malaysia Current Developments and Potential for re-vitalization. MARDI. Paper presented at IPICEX2008, Shah Alam, Malaysia. 